\title{
Rimak International Journal of Humanities and Social Sciences
}

ISSN: 2717- 8293

\section{Samaher Khalil IBRAHIM1 \& Mohammad Saadi LAFTA2}

\section{TECHNICAL INTEGRATION AND ITS APPLICATION FOR ART EDUCATION TEACHERS FROM THE POINT OF VIEW OF SUPERVISORS}

\author{
http://dx.doi.org/10.47832/2717-8293.7-3.5
}

\section{Research Article}

Received:

24/05/2021

Accepted:

27/06/2021

Published:

01/09/2021

This article has been scanned by iThenticat No plagiarism detected

Copyright (C) Published by Rimak Journal, www.rimakjournal.com

Rimar Academy, Fatih, Istanbul, 34093 Turkey All rights reserved

\begin{abstract}
:
The current research problem was established through the following question:

What are the characteristics of technical integration (cognitive, skill, and behavioral)? What are the mechanisms for applying it to art education teachers?

As the current research aims to identify the characteristics of technical integration (cognitive, skill, and behavioral) of art education teachers from the point of view of the supervisors specialization.

The research community consisted of the art education supervisors in the Karkh side, who were (35) supervisors. A sample of (20) supervisors with a specialization in art education on (the Karkh) side were selected, who could be reached through electronic communication means.

To achieve the goal of the current research, the researcher built her research tool represented by the questionnaire, which consisted of (4 domains and 41 paragraphs), as it covered all the characteristics of technical integration (cognitive, skill, and behavioral) that the art education teacher is supposed to display. The most important conclusions are:

1.the majority of art education teachers use the most appropriate methods and decoration.

2.Art education teachers have school exhibitions involving learners to display paintings.
\end{abstract}

Key words: Technical Integration, Art Education.

\footnotetext{
${ }^{1}$ Researcher, Baghdad University, Iraq, Samaherkh.sk@gmail.com, https://orcid.org/0000-0002-2732-3569

${ }^{2}$ Prof. Dr. , Baghdad University, Iraq
} 


\title{
التكامل الفني وتطبيقاته لدى مدرسي التربية الفنية

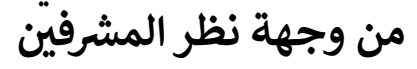

\author{
سماهر خليل ابراهيم3 \\ محمد سعدي لفته
}

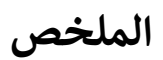

تأسست مشكلة البحث الحالي من خلال التساؤل الآتي:

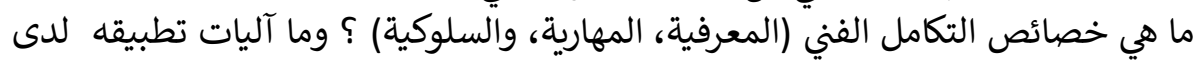

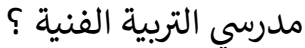
إذ يهدف البحث الحالي التعرف على خصنية خصائص التكامل الفني (معرفيا، مهاريا، سلوكيا) لدى

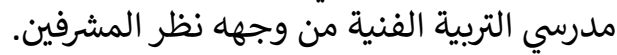

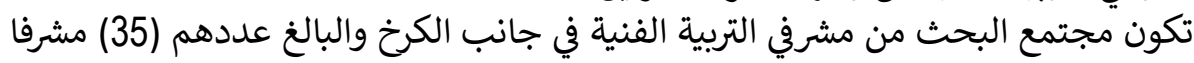

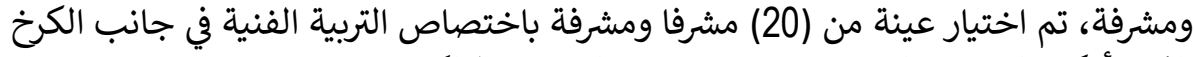

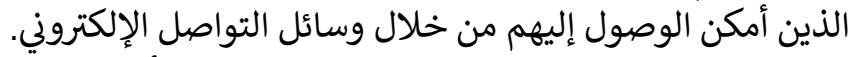

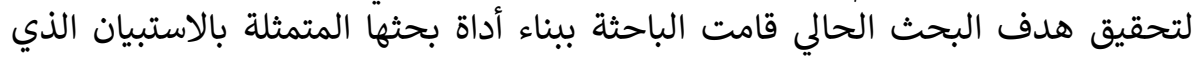

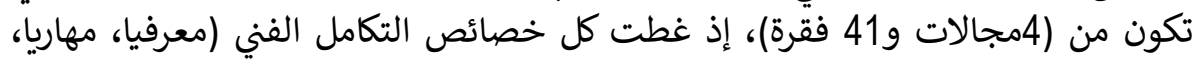

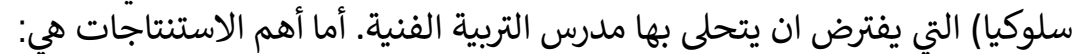

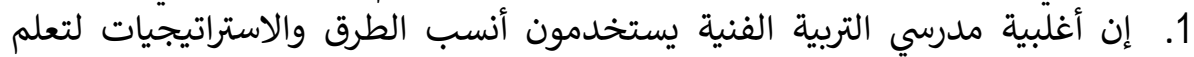
الخط والزخرفة. 2. يمتلك مدرسي التربية الفنية معارض مدرسية بإشراك المتعلمين لعرض اللوحات

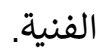
الكلمات المفتاحية: التكامل الفني، التربية الفنية.
\end{abstract}

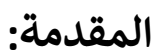

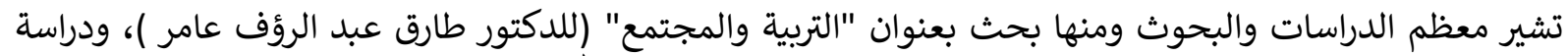

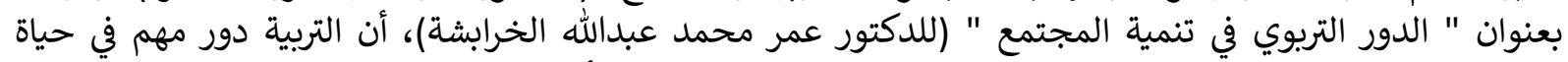

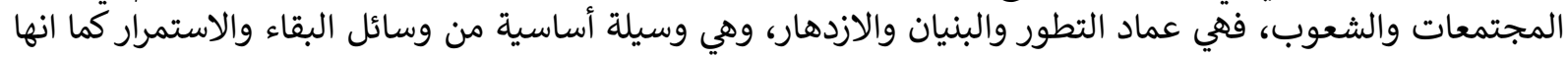

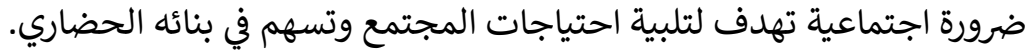

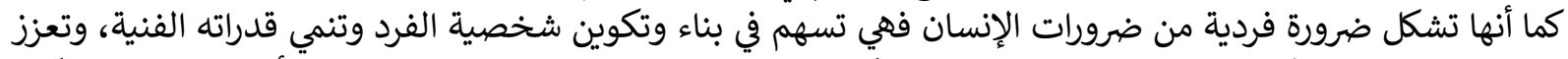

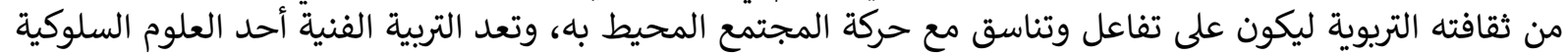

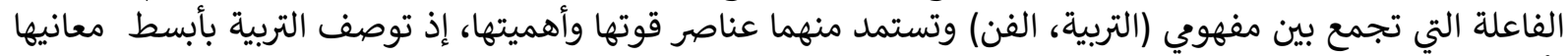

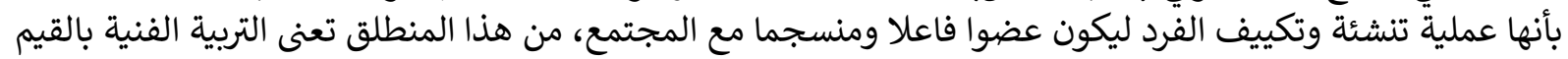

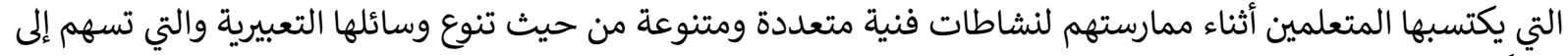
حدّ كبير ببناء وتطوير قدراتهم التعبيرية بوسائل الفن المتنوعة فئنة

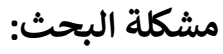

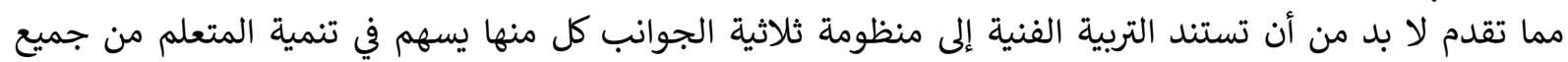

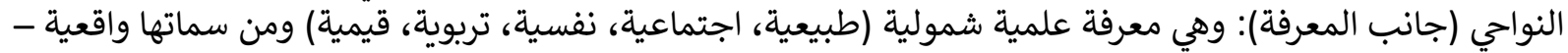

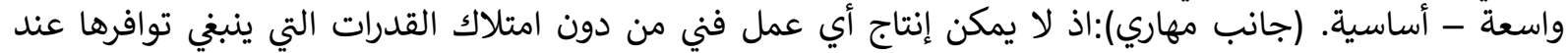

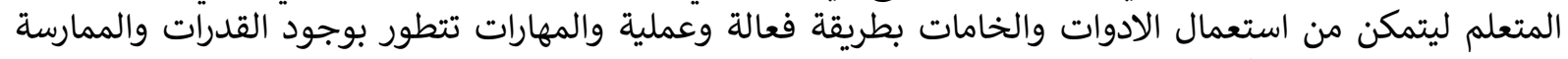

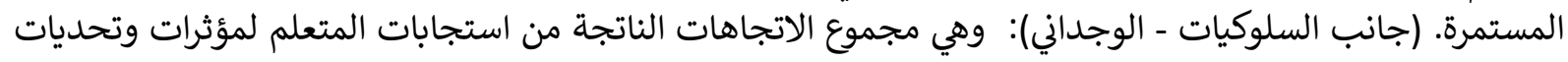




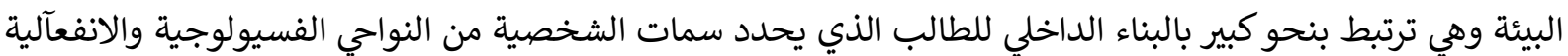

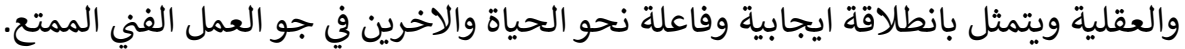

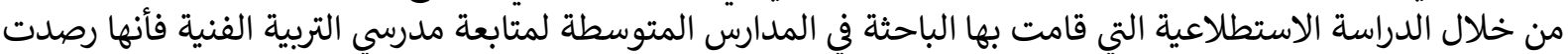

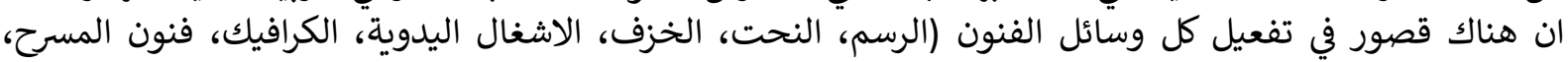

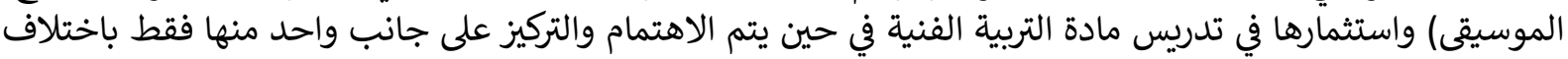

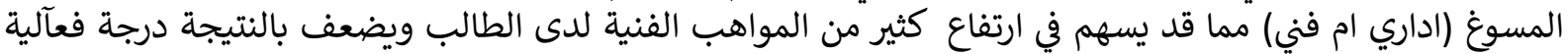

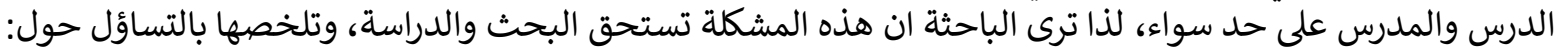

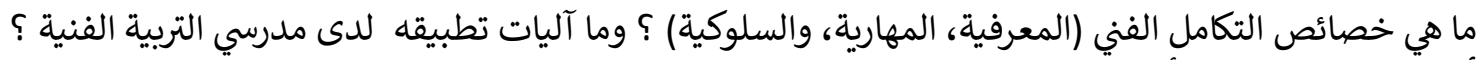

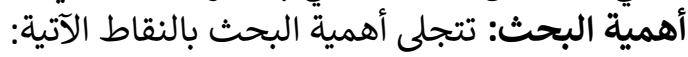
1- يفيد مدرسي مادة التربية الفنية في تعرف خصائص التصاية التكامل الفني (معرفيا، ومهاريا، وسلوكيا) وآليات تطبيقاته في

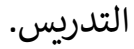
2- يفيد المؤسسات التريوية لوضع برامج وخطط الأنشطة الفنية ويرعى فيها التنوع في وسائل التعبير الفني.

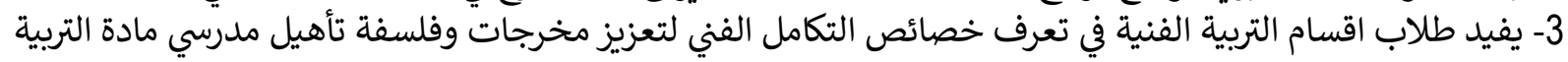
الفنية في المدارس. 4- يشكل البحث اضافة معرفية للمكتبة الفنية والثقافية والتريوية. هدف البحث: يهدف البحث البحث إلى معرفية لئكي التعرف على خصائص التكامل الفني (معرفيا، مهاريا، سلوكيا) لدى مدرسي التربية الفنية من وجهه نظر المشرفين .

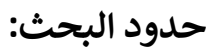
1- الحدود الموضوعية: آليات التكامل الفني في تدريس مادة التربية الفنية.

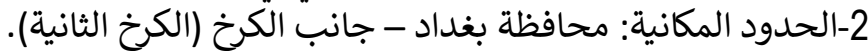

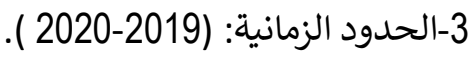
تحديد المصطلحات:

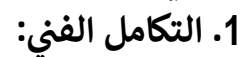

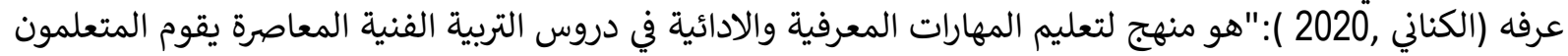

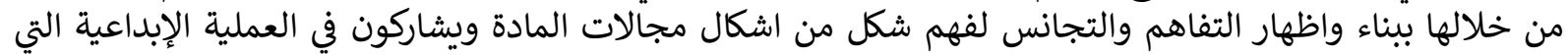

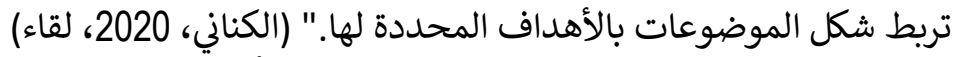

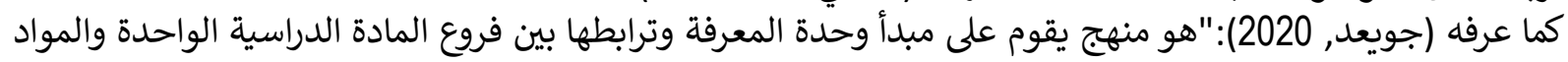

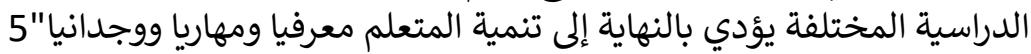

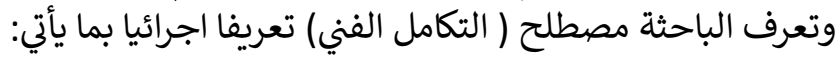

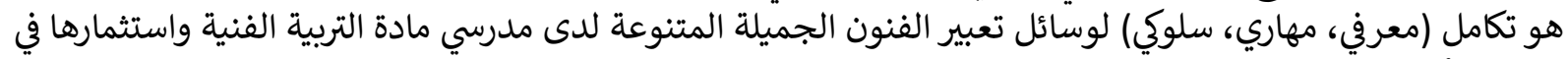

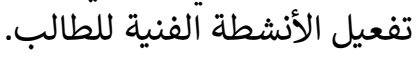

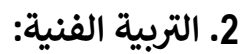

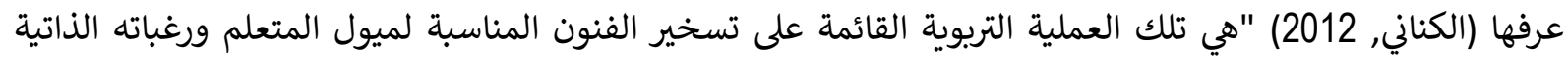

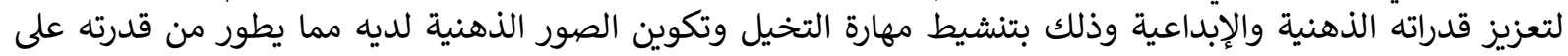

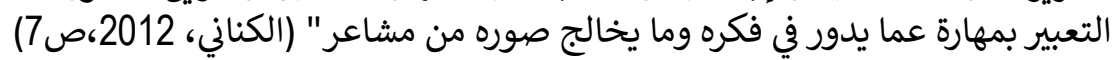

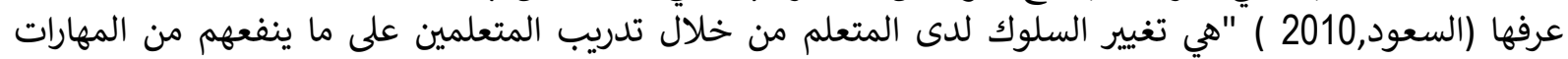

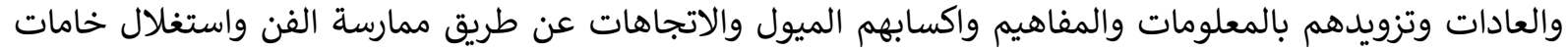

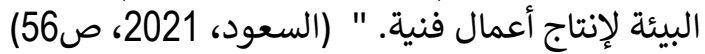

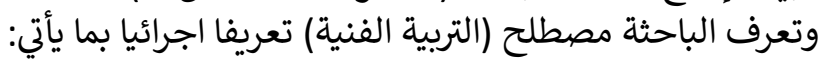

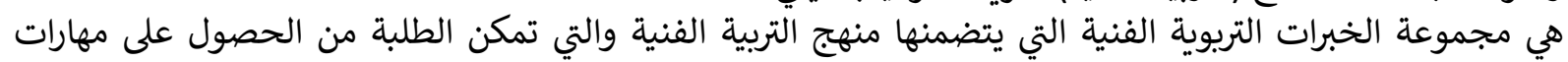

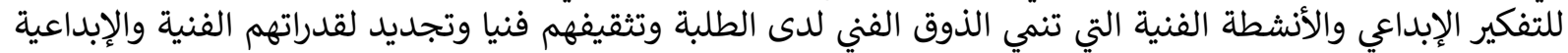
بما يناسب البيئة الاجتماعية المحيطة بهم.

5 حصلت على هذا التعريف من لقاء خاص في 2020 مع أستاذ مساعد محمد جويعد، جامعة بغداد ـ كلية الفنون الجميلة، قسم التربية الفنية 


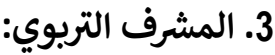

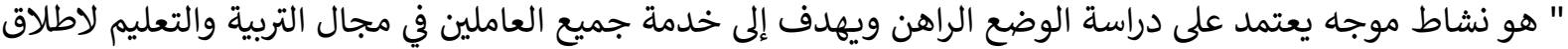

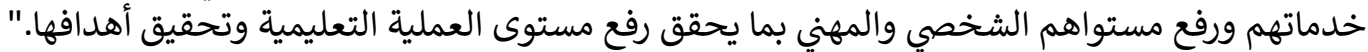

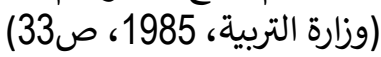

وتعرف الباحثة مصطلح (المشرف التريوي) تعريفا اجرائيا بما يأتي:

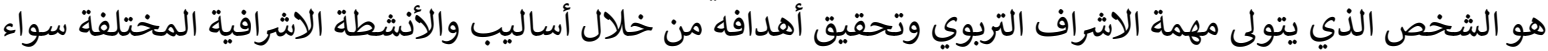
كان هذا الاشراف للمرحلة الابتدائية أو للمرحلة الثانوية.

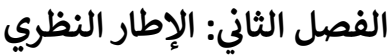

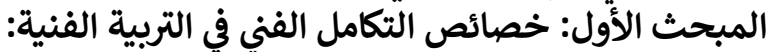

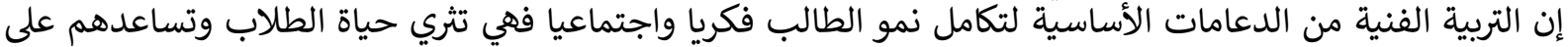

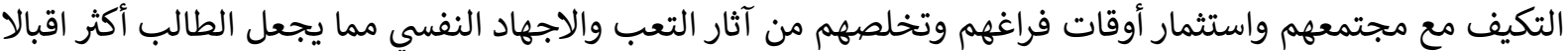

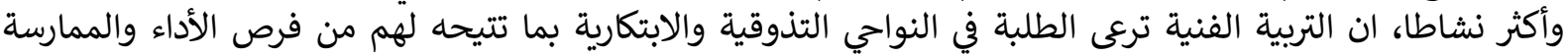

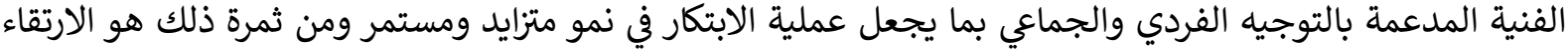

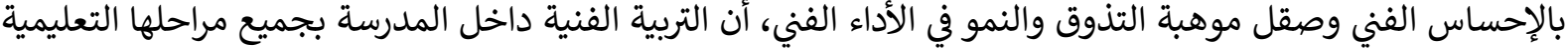

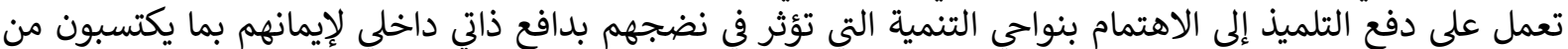

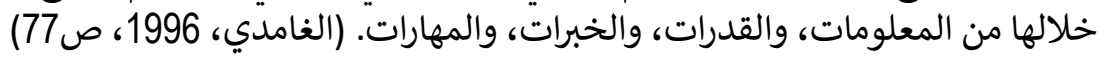

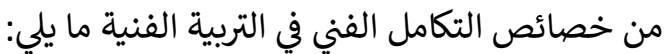

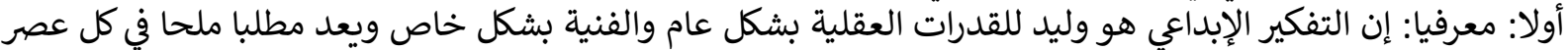

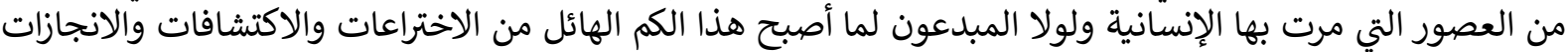

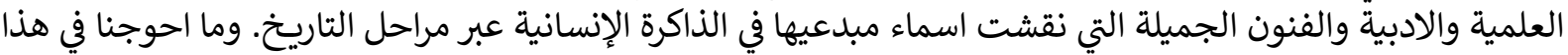

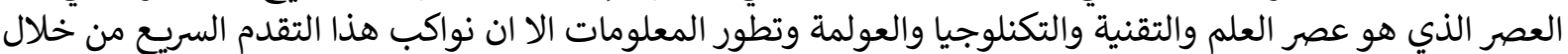

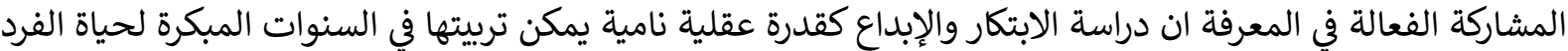

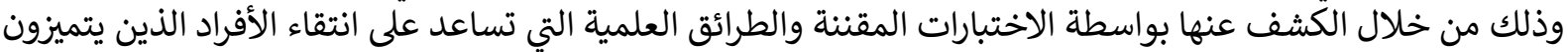

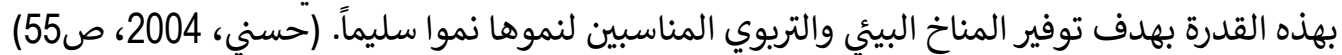

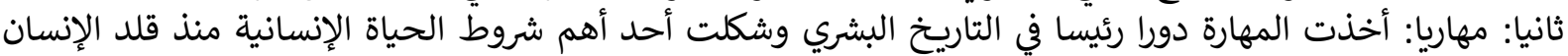

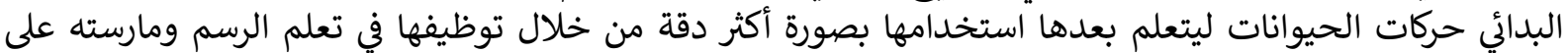

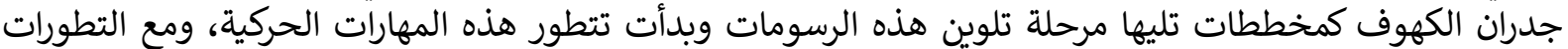

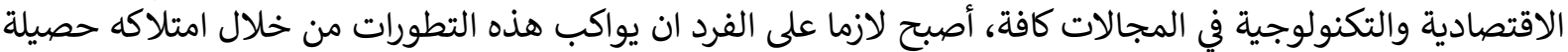

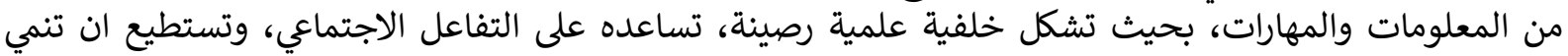

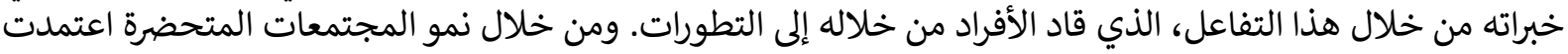

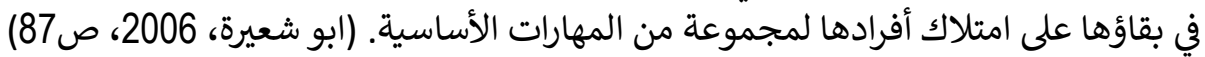

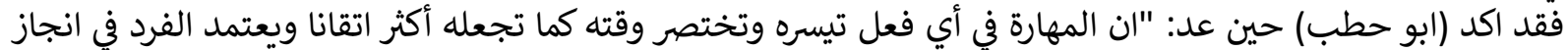

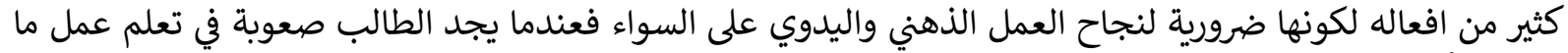

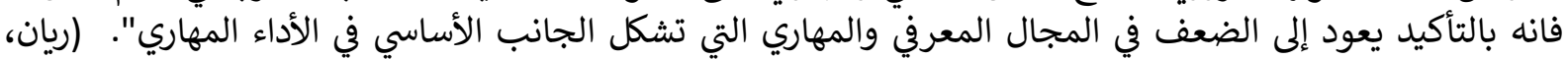

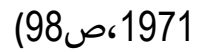

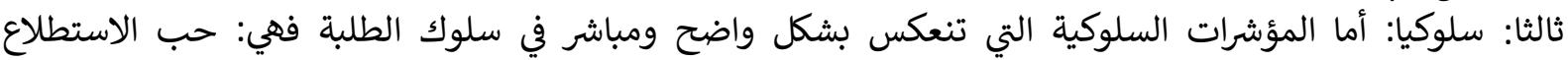

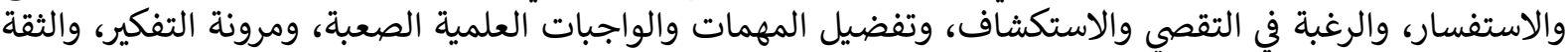

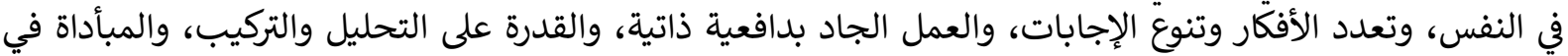

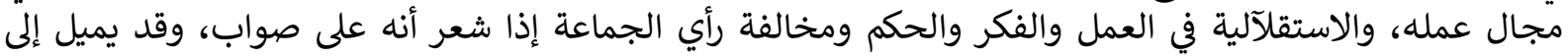

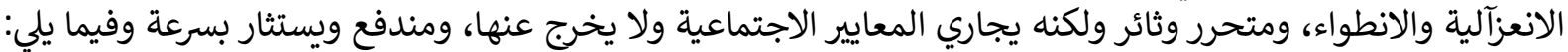

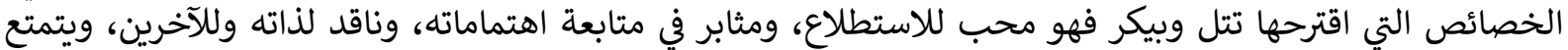

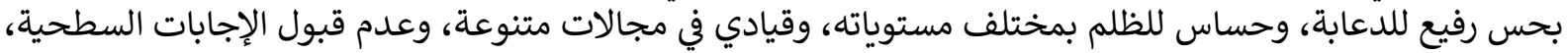

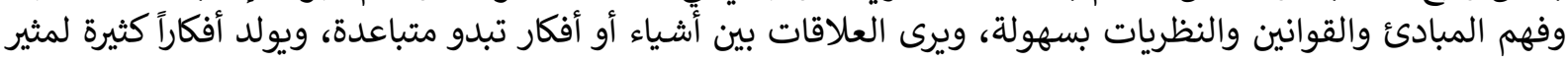
معين).نجاتي، 1975، ص22 (22) 


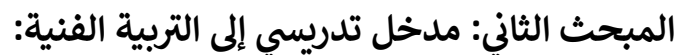

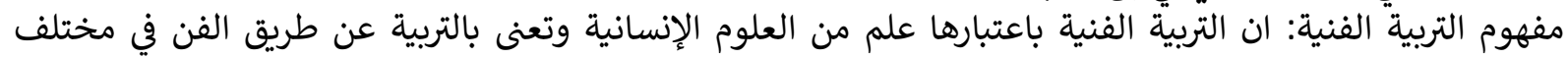

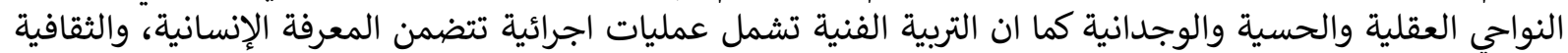

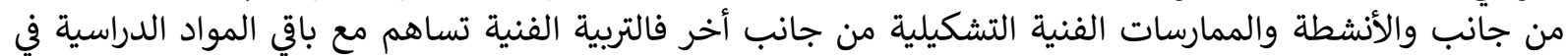

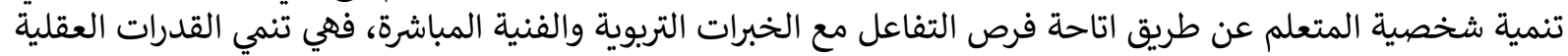

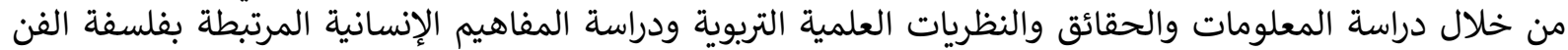

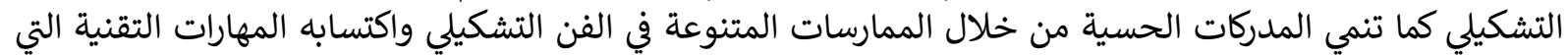

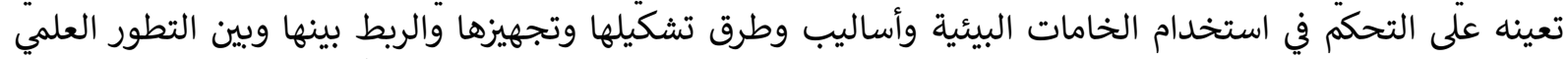

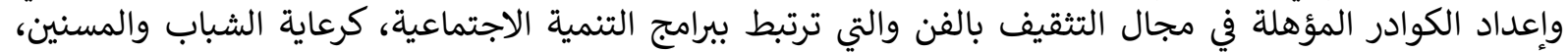
وسائل الاعلام اللغات الخاصة، وذلك للتأكيد على أهمية الفن في حياة الإنسان وبيئته ومجتمعاعهة التية (سليمان، 2000،

ص98)

أهمية التربية الفنية: إذ يلاحظ ان اغلبية معلمين التربية الفنية لم ينجحوا حتى الان في تحقيق أهداف التربية الفنية

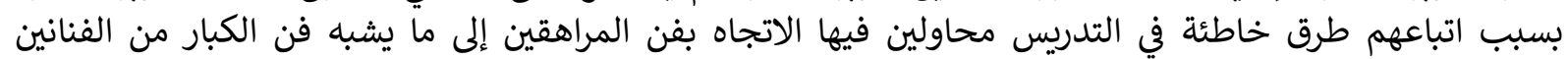

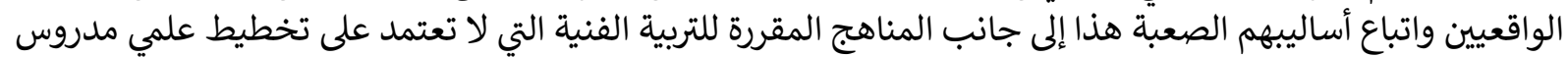

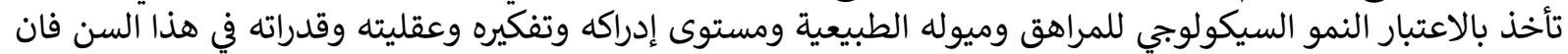
هذه المناهج ظلت ماعتيار النوتمدة على مواصفات واقعية بصرية تفرض على المعلم ان ينقلها إلى طلابه بطريقة آلية. (جودي،

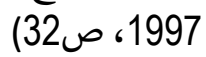

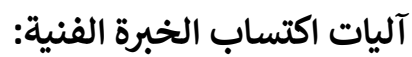

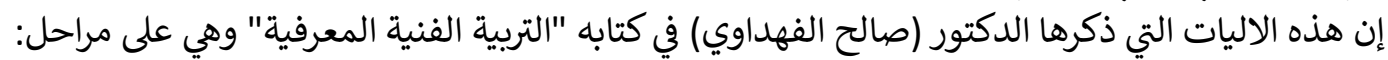

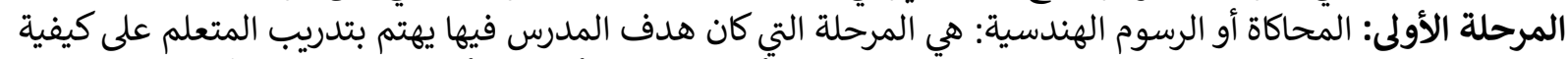

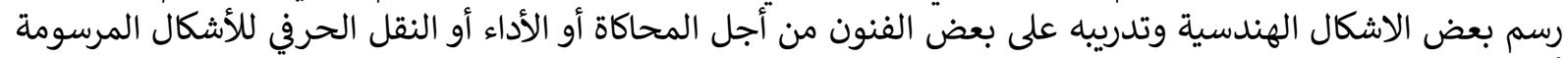

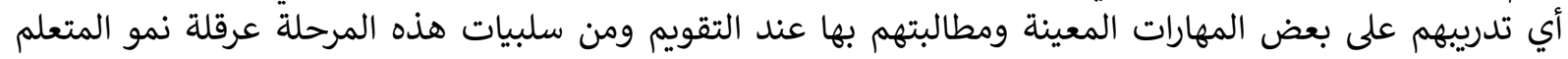

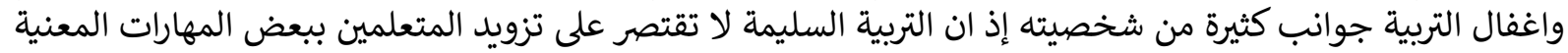

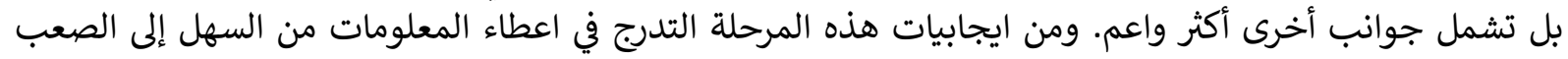

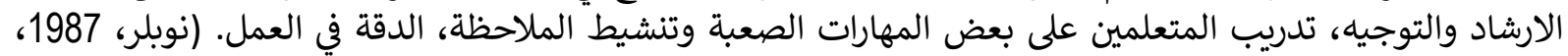

ص12).

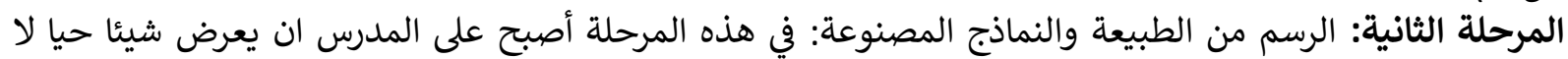

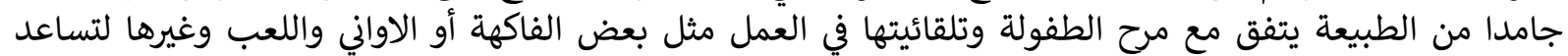

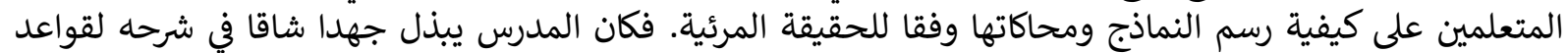

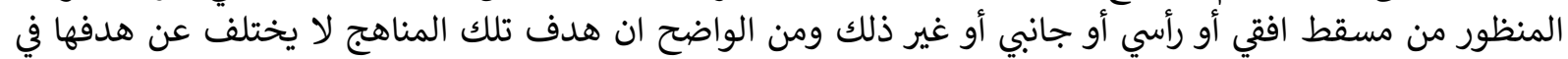

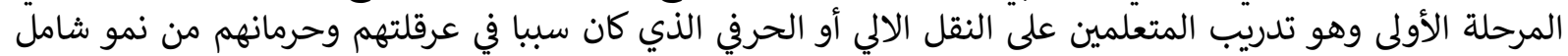

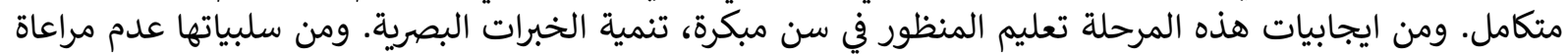

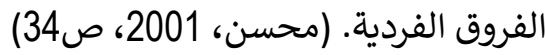

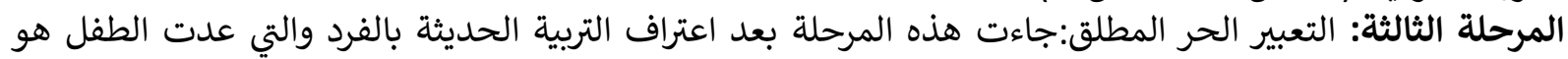

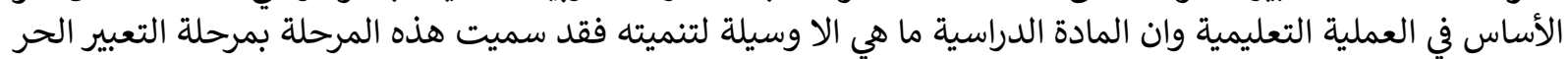

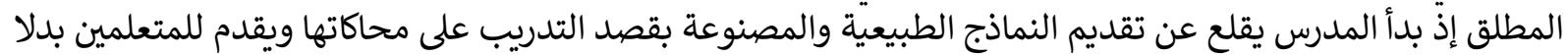

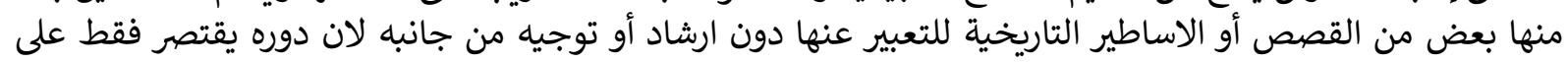

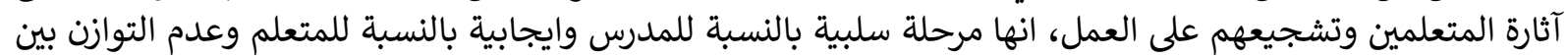

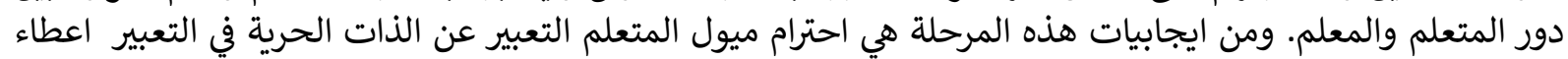

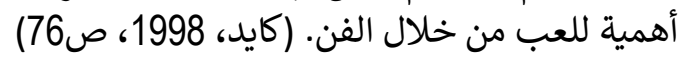

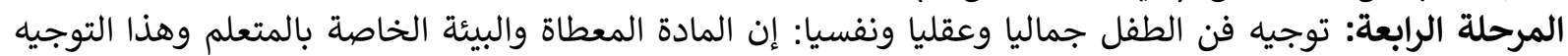

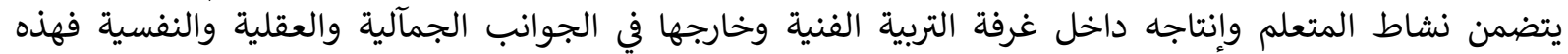

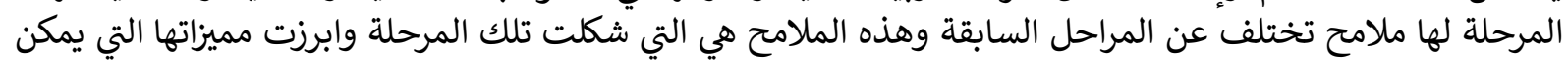

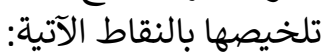
1. الاهتمام بتفاعل العوامل التي تؤثر في النشاط الفني. 


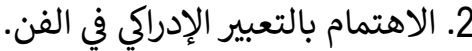

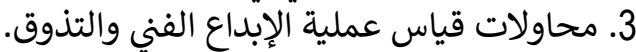

4. 1. الاهتمام بالتوجيه الفردي للمتعلميلمين.

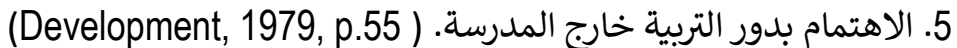

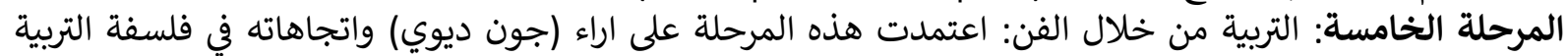

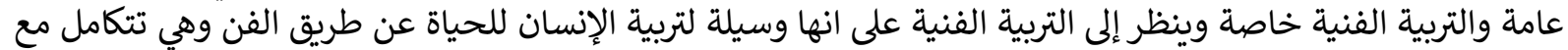

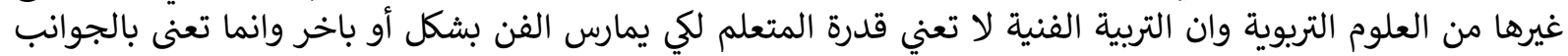

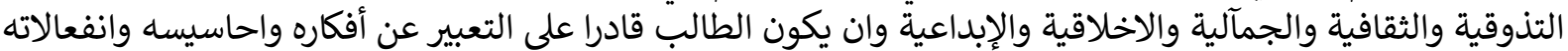

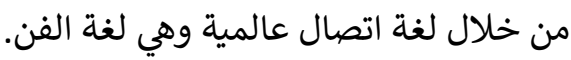

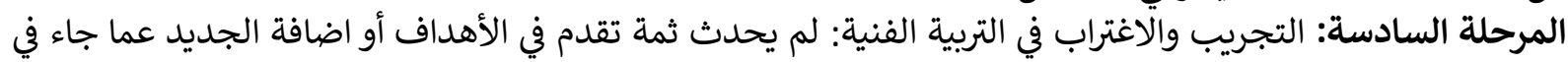
المراحل السابقة سوى الاتجاه نحو البيئة وقضاياها. (Klein bauer, 1987, p.77)

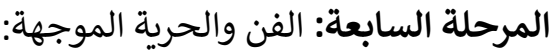

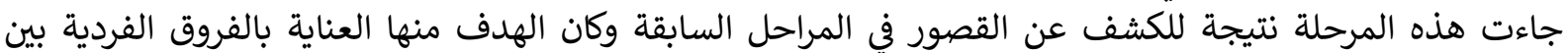

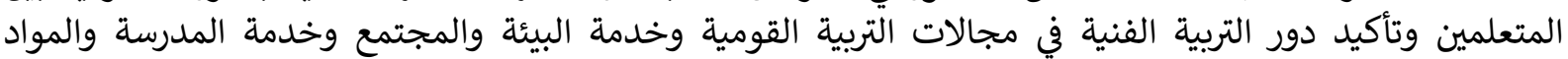

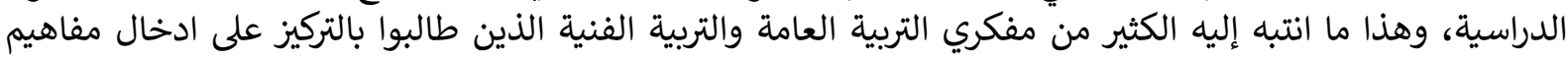

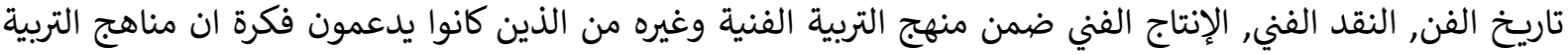

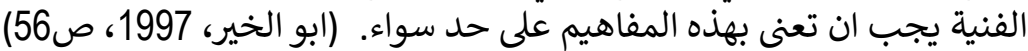

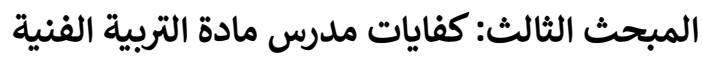

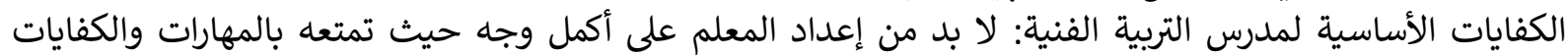

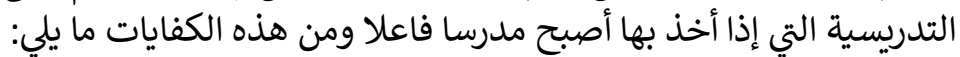

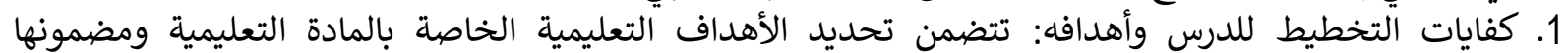
والنشاطات والوسائل الملائمة لهات 2. كفايات تنفيذ الدرس: وتشمل علئ على تنظيم الخئ الخبرات التعليمية والنشاطات المرافقة لها وتوظيفها في العملية التعليمية.

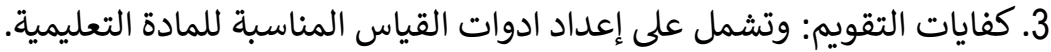

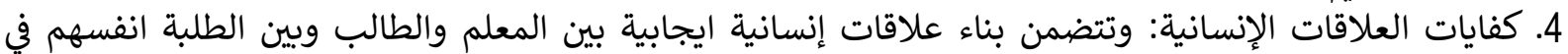

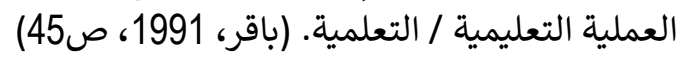

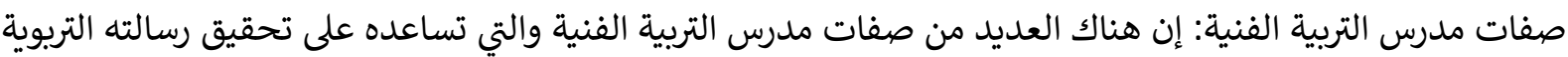
على اكمل وجه وفيما يلي أهم هذه الصفية الصفات:

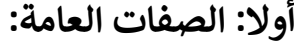
1. حث الطلبة على السلوك الحسن وتنمية الحس الجمالي لديهم.

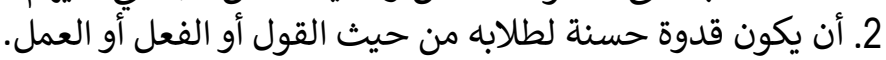

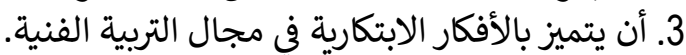

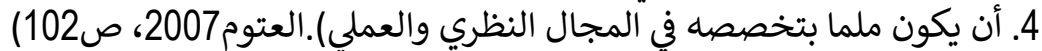

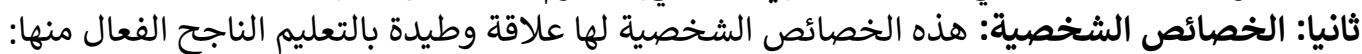

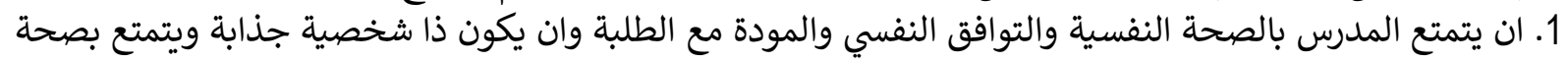
جسمية وعقلية جيدة واتزان عاطفين. 2. ان يكون عادلا امينا حازما، صريحا، مرنان عاني، صادقا بأقوان القواله وافعاله، حساسا لمشاعر الاخرين.

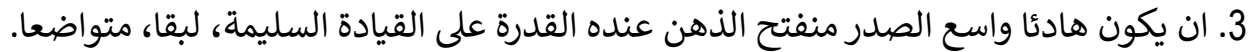

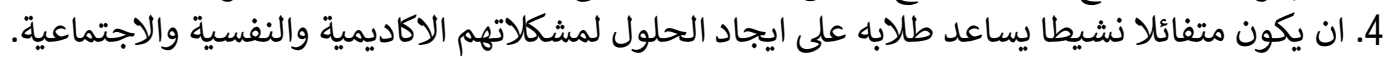

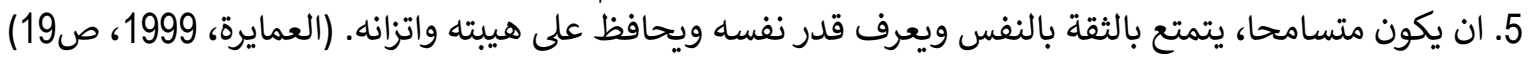

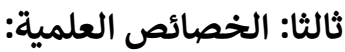
1. الإعداد الاكاديمي والمهنية العائية العالي للمدرس لكي يستطيع مساعدة الطلاب عندما يطلبون منه ذلك، وان يكون ملما

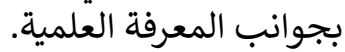
2. القدرة على اتقاء الأنشطة والوسائل والأساليب المناسبة للدرس الواحد والتئي بوجودها تحقيق الأهداف التعليمية المرسومة في ضوء الإعداد التربوي. 
3. ان يكون ملما بأسس القياس والتقويم لتحليل وتفسير نتائج طلابه وان يعمل باستمرار على التغذية الراجعة لمسيرته التعليمية.

4. ان يهتم بنتاج تعلم الطلاب فيقوم بعرضه لهم ولأولياء امورهم والمسؤولين التربويين. (الحيلة، 2002، ص20)

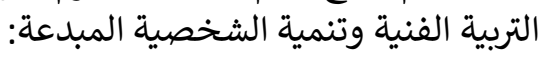

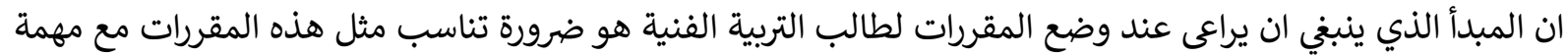

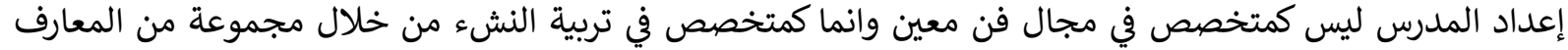

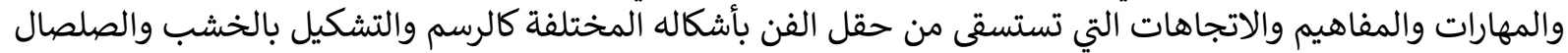

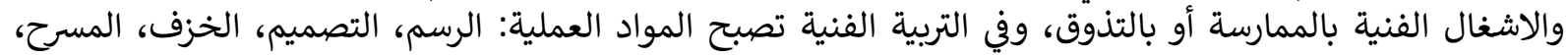

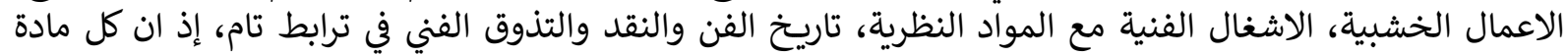

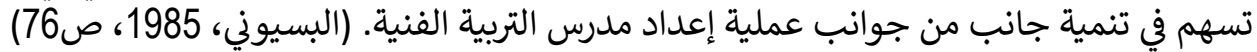

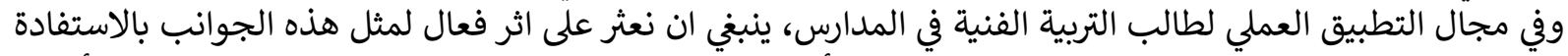

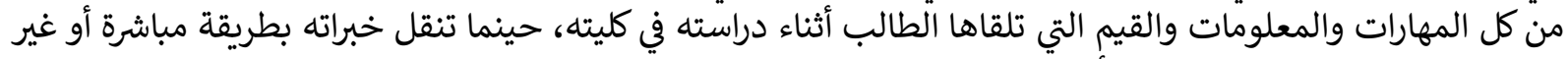

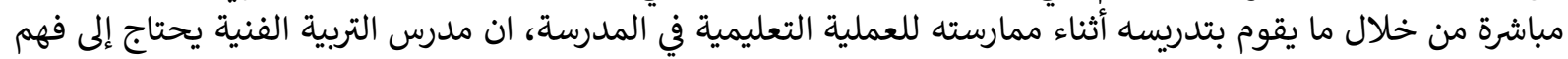
لطبيعة التلميذ في المرحلة التي يقوم بالتدريس أناء ميمارسته فيها.

\section{المبحث الرابع:التخطيط للتدريس لمهارات التربية الفنية

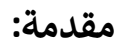

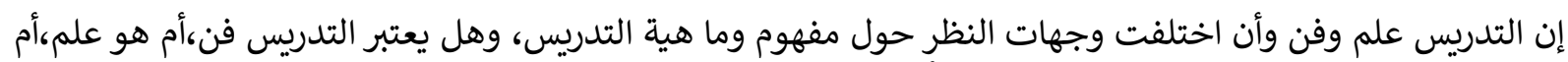

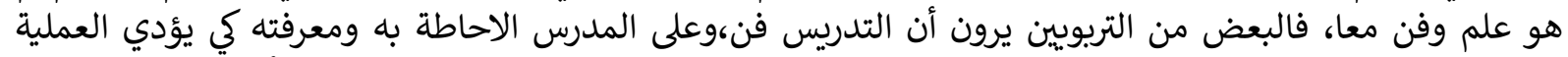

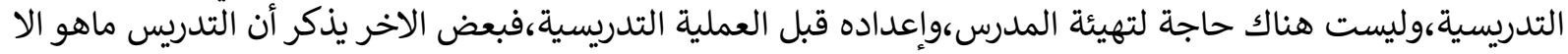

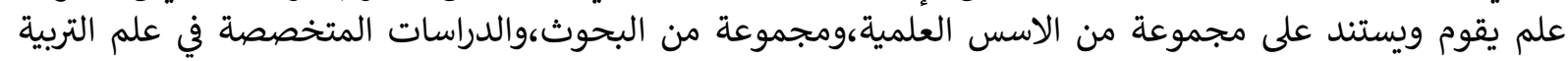

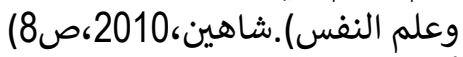

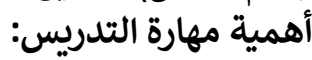

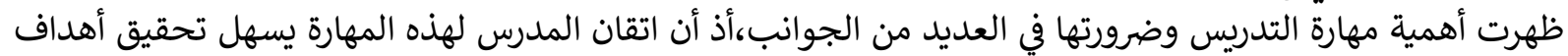

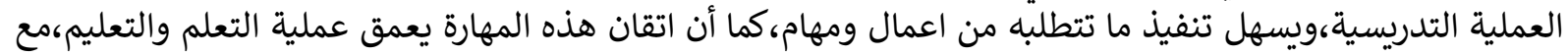

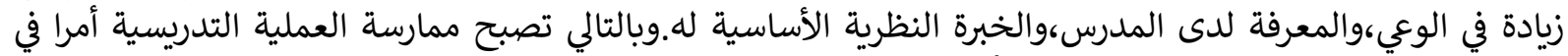

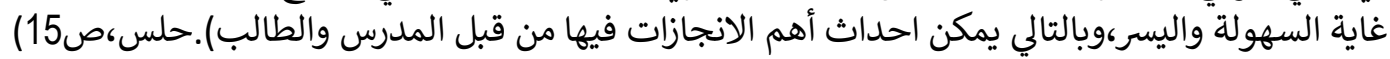

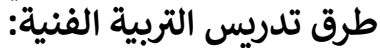

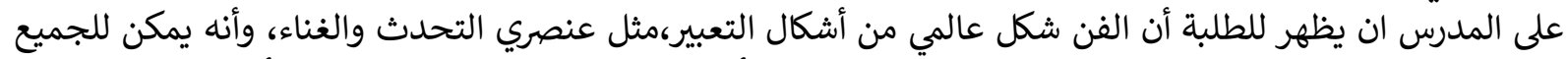

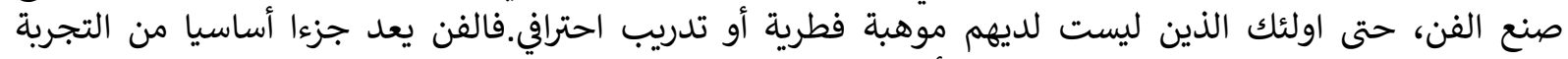

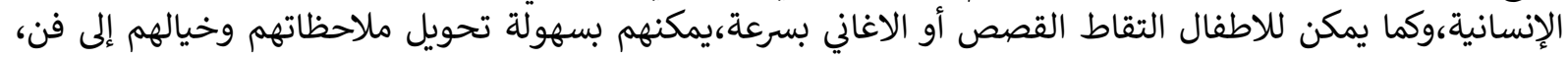

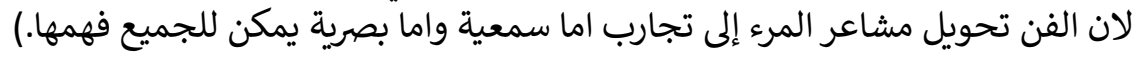
كيفية التخطيط لدرس التربية الفنية:

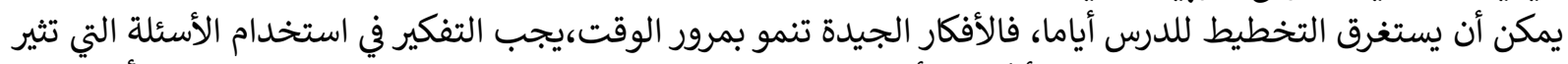

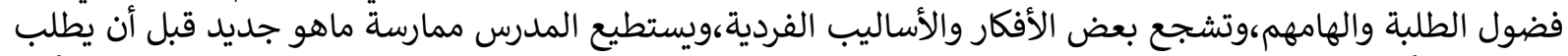

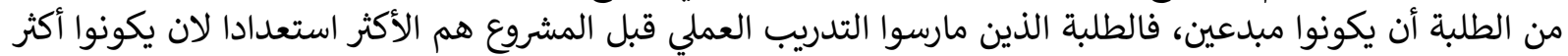

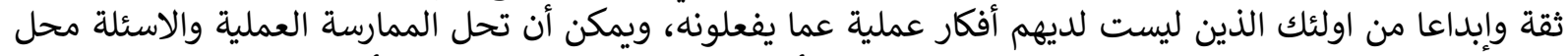

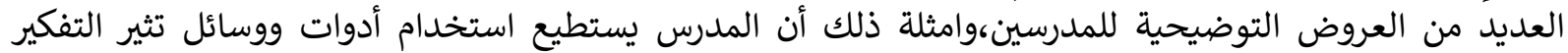

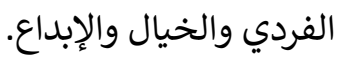

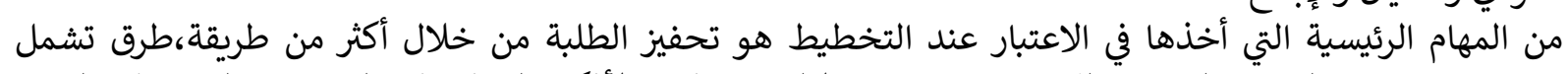

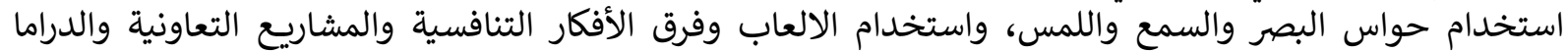
والرقص وتجريب الشعر،وغير ذلك من الطرق التي يراها المدرس مناسبة للطلبة).

$$
\text { مهارات التدريس الإبداعي والتدريس الفعال: }
$$

ذكر (مجدي عزيز،2000،صريسي والإبندريس أن التدريس الفعال يقوم على بعدين هما: 
مهارة المدرس وبراعته في خاق الآثارة العقلية والفكرية لدى طلبته،والصلة الإيجابية بين المدرس والطلبة،وأنماط العواطف والعلاقات التي تثير دافعية الطلبة.

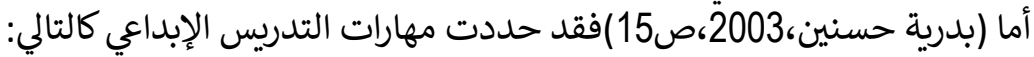

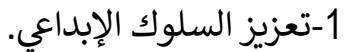
2- 2-عرض وابداعات العلمًاء.

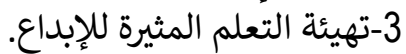

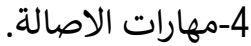

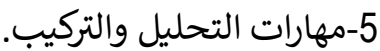

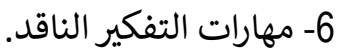

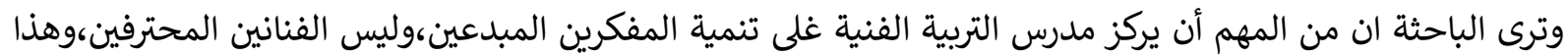

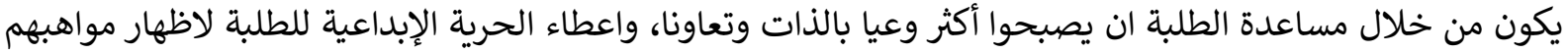

ومهاراتهم.

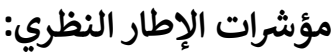

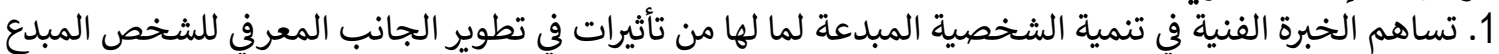

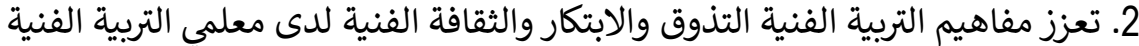

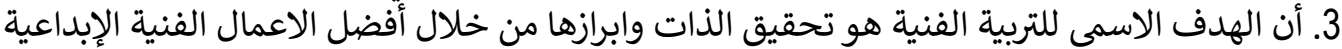

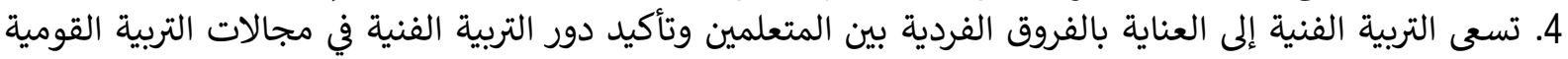

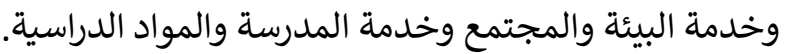
5. يفترض ان يكون إعداد المدرس على الماعل وخل وجه حيث تمتعه بالمهارات والكفايات التدريسية التي إذا أخذ بها أصبح مدرسا فاعلا. 6. أن الاهتمام بالتخصص الإلتاعي الدقيق من قبل مدرسي التربية الفنية سواء بالرسم أو النحت أو الموسيقى يساعد على زيادة

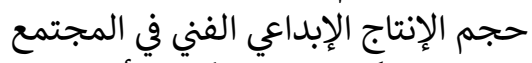
7. تؤثر سيكولوجية المكإِية الفني للأعمال الفنية في درس التربية الفنية على تطوير الفنون وارتقائها إذ كلما كانت البيئة الفنية مناسبة تطورت العملية الفنية التريوية.

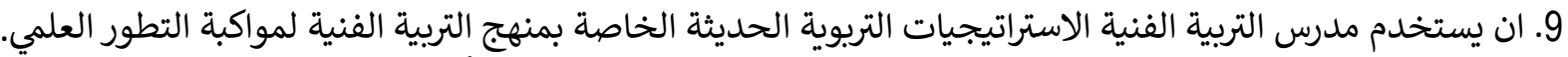

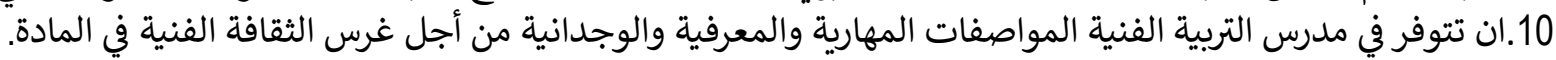

\section{الفصل الثالث: إجراءات البحث البحث}

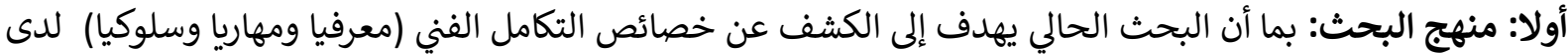

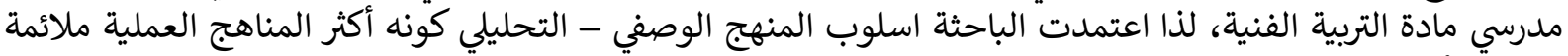
لتحقيق أهداف البحث البحث الترالية الفنية ثانياً:- مجتمع البحثث: يتألف مجتمع البحث من مشرفي التربية الفنية في جانب الكرخ والبالغ عددهم (35)مشرفا

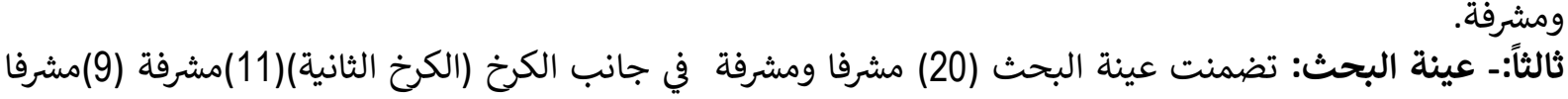

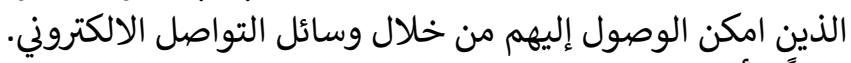

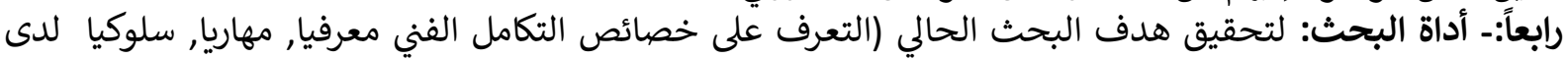

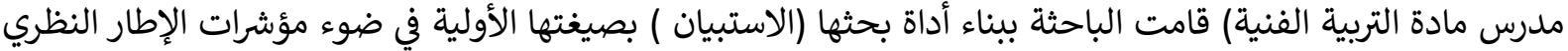

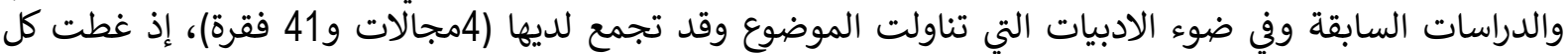

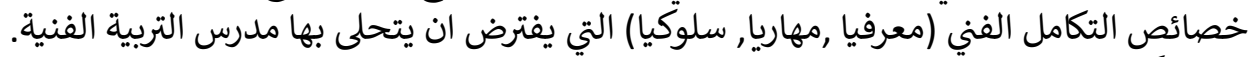

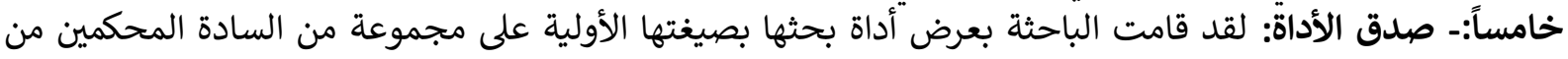

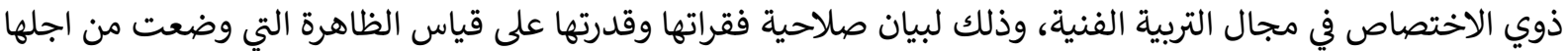

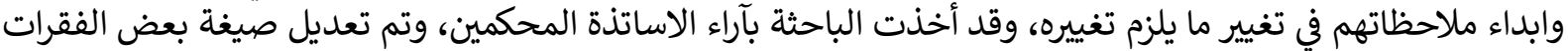

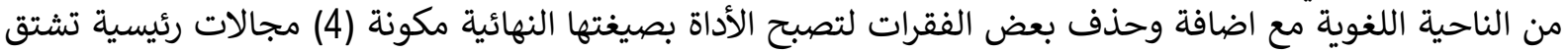

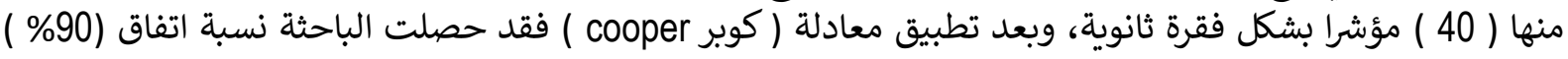


بين المحكمين على صلاحية الأداة وفي ضوء اراء السادة الخبراء البالغ عددهم (5) فقد تم وضع بدائل للإجابة لتحديد

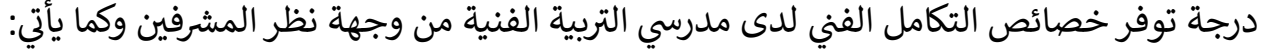

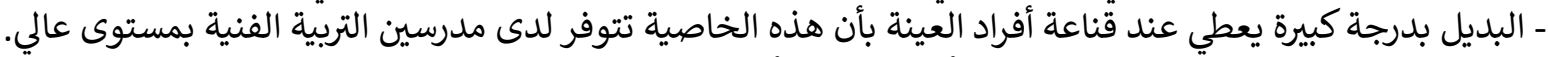

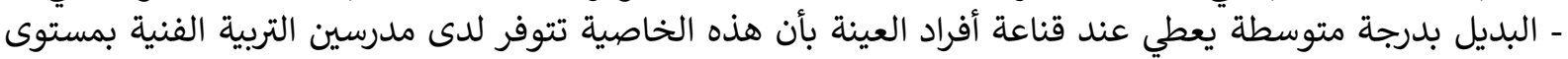
أقل من الدرجة العآلية.

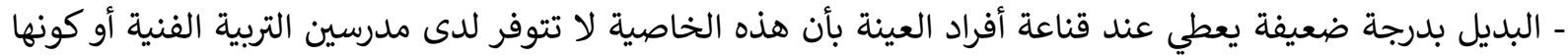

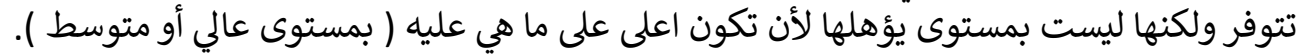

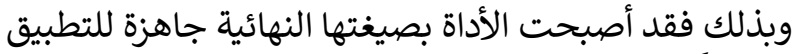

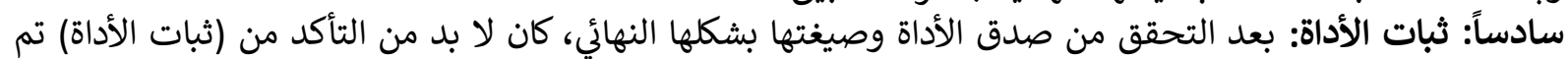

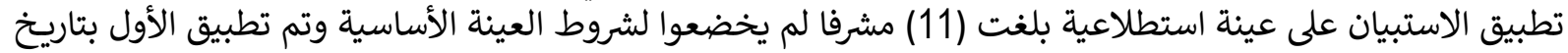

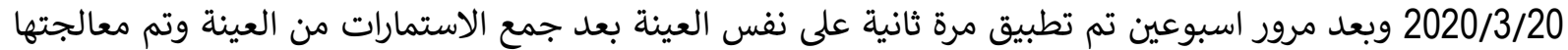

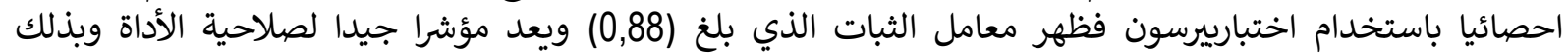

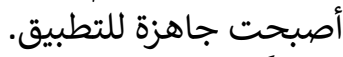

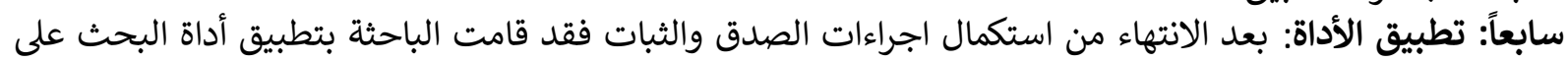

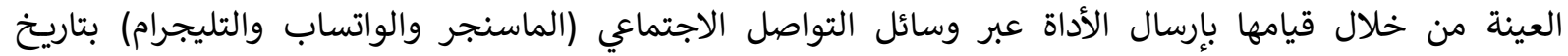

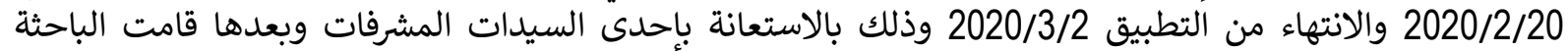

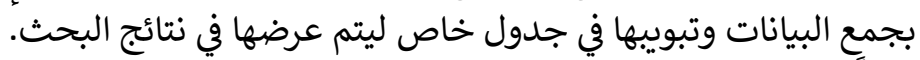

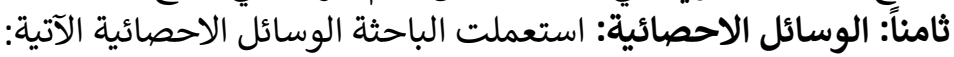

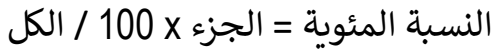
cooper

100 x مجموع حالات الاتفاق بين التحليلين معادلة كوبر = مجموع حالات الاتفاق وعدم الاتفاق

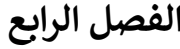

النتائج ومناقشتها: من أجل تحقيق هدف البحث وهو التعرف على خصائ خصائص التكامل الفني (معرفيا، مهاريا، سلوكيا)

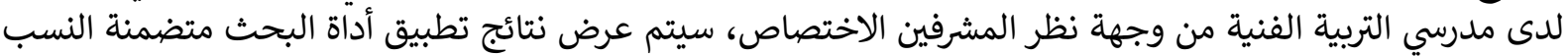

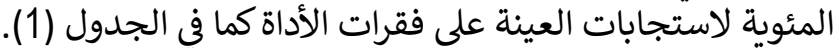
جدول (1) يبين استجابات العينة حول فقرات الأداة الخاصة بتقويم الإنة خصائص التكامل الفني لدى مدرسي التربية الفنية.

\begin{tabular}{|c|c|c|c|c|c|c|}
\hline المئون & 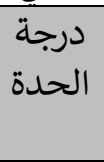 & ضعيف & متوسط & جيد & 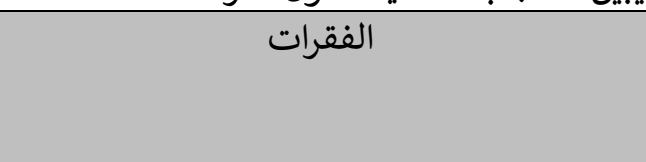 & 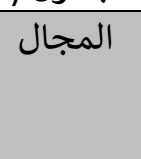 \\
\hline 0,90 & 2,7 & 1 & 4 & 15 & يستخدم مواد طبيعية وصناعية للأشغال & \multirow{7}{*}{ التشكهيلية } \\
\hline 0,90 & 2,7 & 1 & 4 & 15 & يعمل ورشة للأشغال اليدوية & \\
\hline 0,46 & 1,14 & 13 & 6 & 1 & مادة التربية الفنية في الرسم المناسب لكيفية تنفيذ & \\
\hline 0,58 & 1,75 & 6 & 13 & 1 & 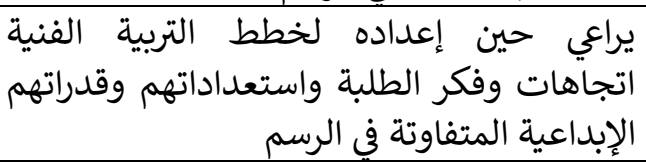 & \\
\hline 0,46 & 1,14 & 13 & 6 & 1 & تخطيط الترظم مصادر البيئة والخبرات الميدانية في الفنية في موضوع & \\
\hline 0,92 & 2,75 & 1 & 3 & 16 & الأنسيخب لتعليم وتعلم الخط والأساليب والاستراتيجيات & \\
\hline 0,87 & 2,60 & 1 & 6 & 13 & يحدد المدركات والمفاهيم الأساسية والفرعية & \\
\hline
\end{tabular}




\begin{tabular}{|c|c|c|c|c|c|c|}
\hline & & & & & المتضمنة في موضوع الخط والزخرفة & \\
\hline 0,83 & 2,50 & 2 & 6 & 12 & يعمل معارض لرسومات المتعلمين & \\
\hline 0,83 & 2,50 & 2 & 6 & 12 & والأعمال الفنعلمين في الرسم الحوار حول اللوحات & \\
\hline 0,95 & 2,85 & 1 & 1 & 18 & استخدام مجموعة الألوان الساخنة والباردة في & \\
\hline 0,93 & 2,80 & 0 & 2 & 18 & 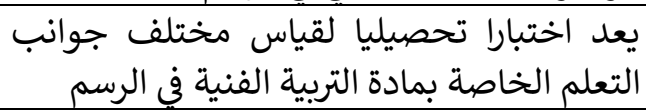 & \\
\hline 0,37 & 1,1 & 18 & 2 & 0 & يراعي تكامل موضوعات الموسيقى & \multirow{6}{*}{ 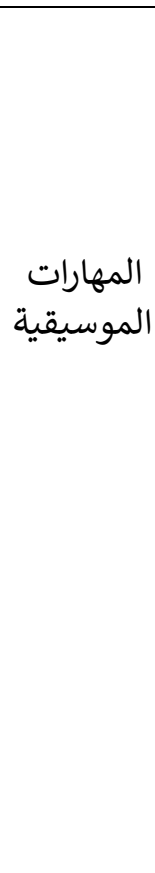 } \\
\hline 0,37 & 1,1 & 18 & 2 & 0 & 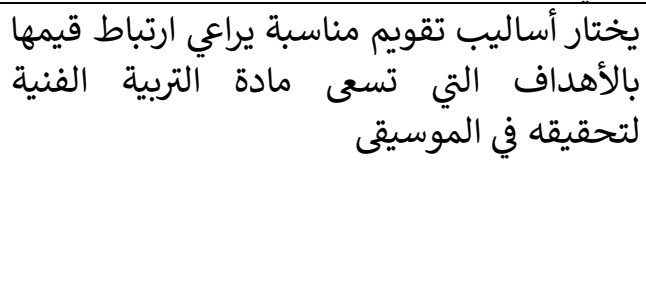 & \\
\hline 0,42 & 1,25 & 16 & 3 & 1 & الدرس مق الموسيقى جيدة وخطوات مناسبة لسير & \\
\hline 0,42 & 1,25 & 16 & 3 & 1 & يعناصيخ السئلة جيدة الأساسية فنبا فيها التكرار ومتعلقة & \\
\hline 0,38 & 1,15 & 18 & 1 & 1 & 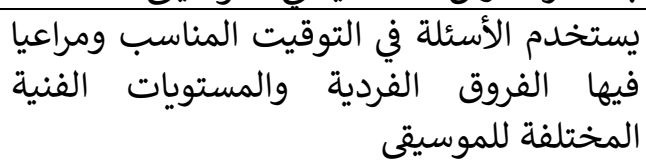 & \\
\hline 0,38 & 1,15 & 18 & 1 & 1 & الموسئ الفصل للمناقشة جيدا بحيث والنقد والتحليل الفناخ الفني & \\
\hline 0,46 & 1,14 & 13 & 6 & 1 & 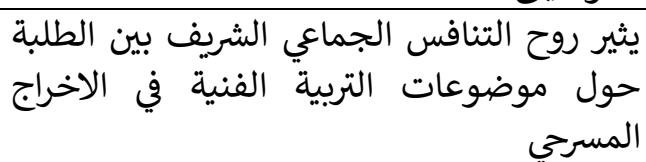 & \multirow[t]{8}{*}{ التمثيلية } \\
\hline 0,93 & 2,80 & 0 & 2 & 18 & ويتمتع بعلاقة حب ومودة وارتياح وسرور بينه & \\
\hline 0,46 & 1,14 & 13 & 6 & 1 & بكفاءة عآلية بالتمثيل المسرحي بالمجات الفنية المختلفة & \\
\hline 0,46 & 1,14 & 13 & 6 & 1 & 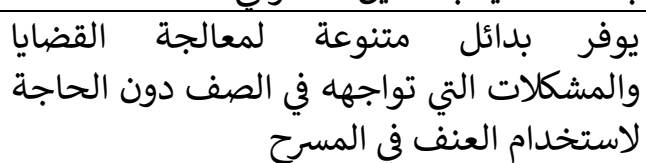 & \\
\hline 0,87 & 2,60 & 1 & 6 & 13 & لديى طلبته في المسرح التعليمي الذي يثري الخيال الفني & \\
\hline 0,77 & 2,30 & 4 & 6 & 10 & 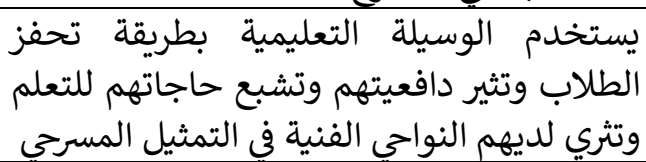 & \\
\hline 0,42 & 1,25 & 16 & 3 & 1 & 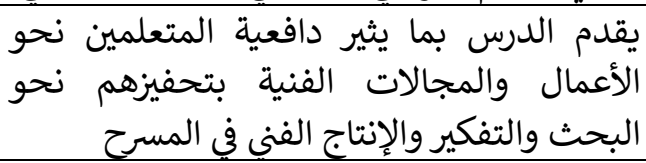 & \\
\hline 0,63 & 1,90 & 6 & 10 & 4 & الأسطاسية فلش الدرح مسبقا وبثناء التمثيل المسرحي العناصر & \\
\hline
\end{tabular}




\begin{tabular}{|c|c|c|c|c|c|c|}
\hline 0,70 & 2,10 & 4 & 10 & 6 & 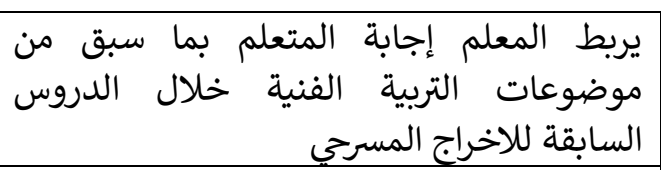 & \\
\hline 0,55 & 1,65 & 13 & 1 & 6 & 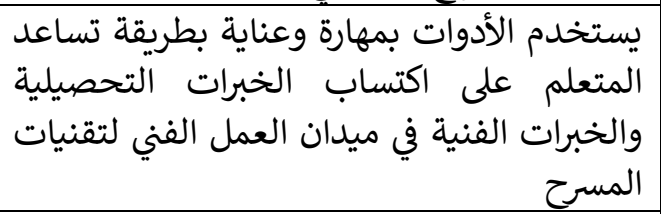 & \\
\hline 0,67 & 2,00 & 4 & 12 & 4 & لتوضريب الفكرة في التمثيل المسرول للحلول المناسبة & \\
\hline 0,67 & 2,00 & 4 & 12 & 4 & فهم الرموز المستوحاة من الفن الشعبي في & \\
\hline 0,67 & 2,00 & 4 & 12 & 4 & التسرحيم الجمالي لأسس وعناصر العمل الفني & \\
\hline 0,60 & 1,80 & 10 & 4 & 6 & 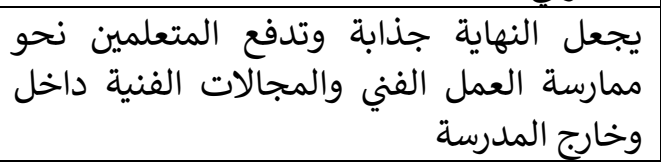 & \multirow{8}{*}{ 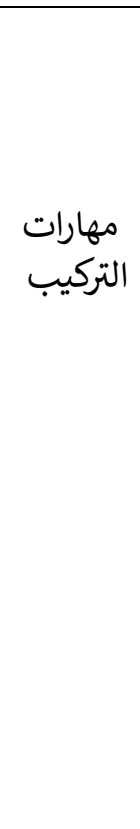 } \\
\hline 0,73 & 2,20 & 6 & 4 & 10 & المختلفة مفردات الاختبارات التحصيلية بأنواعها & \\
\hline 0,60 & 1,80 & 10 & 4 & 6 & 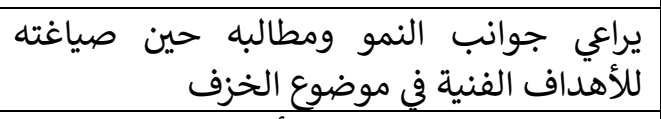 & \\
\hline 0,48 & 1,45 & 13 & 5 & 2 & في الاعمال الخزفِية لتحنقيق أهداف التربية الفنية & \\
\hline 0,53 & 1,60 & 12 & 4 & 4 & حسب فيدد الكفايات الفنية الملائمة لدرس النحت & \\
\hline 0,58 & 1,75 & 9 & 7 & 4 & يوضح معنى التكوين الفني في النحت ومستوياته & \\
\hline 0,48 & 1,45 & 13 & 5 & 2 & في الخزف يصنف الكفايات الفنية ويوظفها & \\
\hline 0,73 & 2,20 & 6 & 4 & 10 & العملم الفنظي & \\
\hline
\end{tabular}

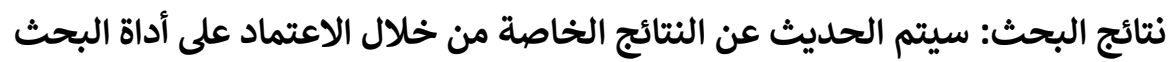

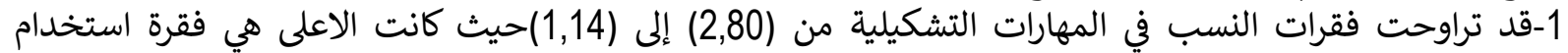

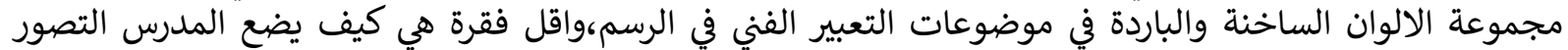

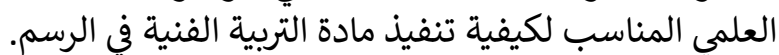

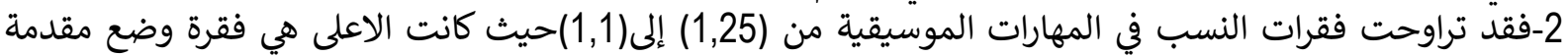

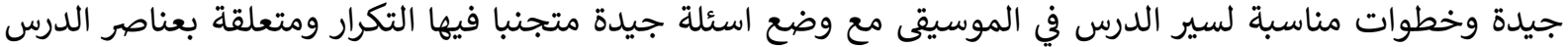

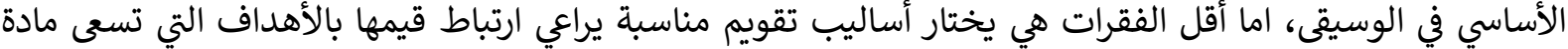
التربية الفنية لتحقيقها في الموسيقى الوسي.

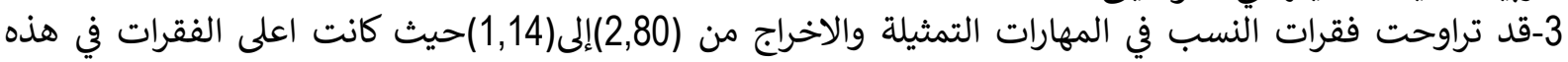

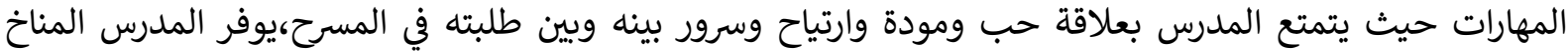

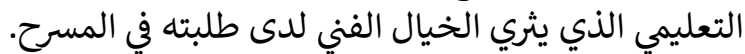

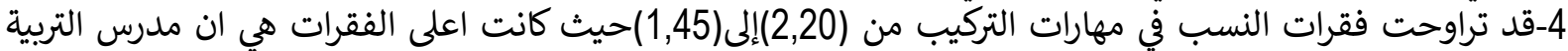

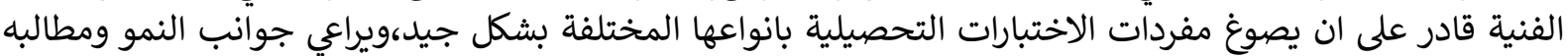

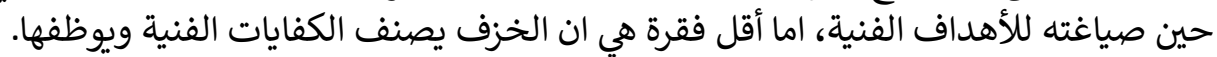

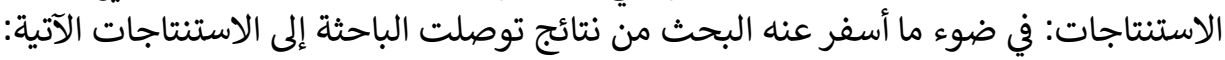


1. ان اغلبية مدرسي التربية الفنية يستخدمون أنسب الطرق والاستراتيجيات لتعلم الخط والزبر الزخرفة.

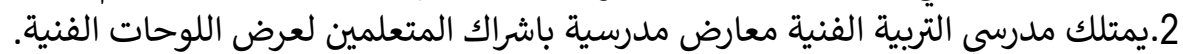

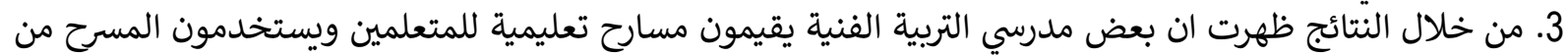

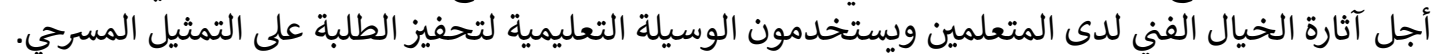

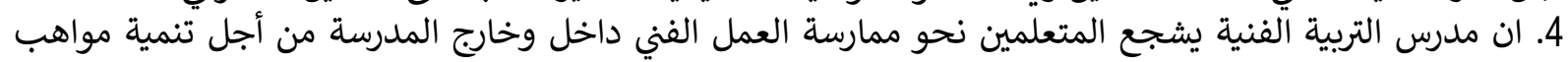

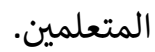
5. من خلال النتائج ظهرت ان مدرسي التربية الفنية لا يملكون مهارات تدريس الموسيقى ومما يدل على انه في مرحلة دراسة

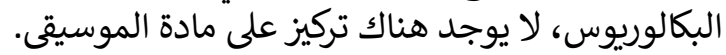

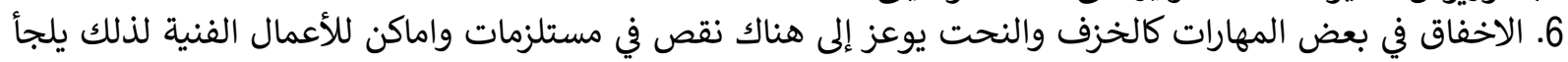

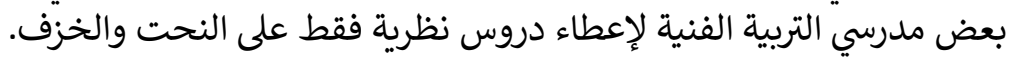

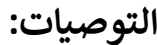
1. ضرورة الاهتمام بتعليم طلبة قسم التربية الفنية لمادتي الخزف والنحت.

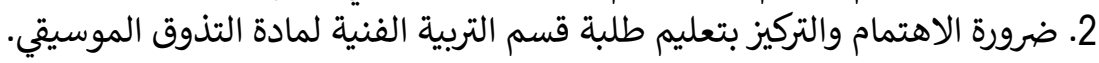

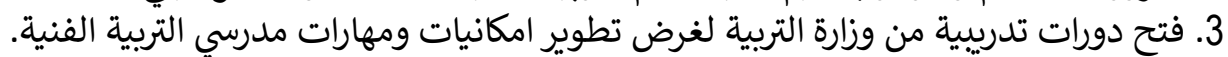

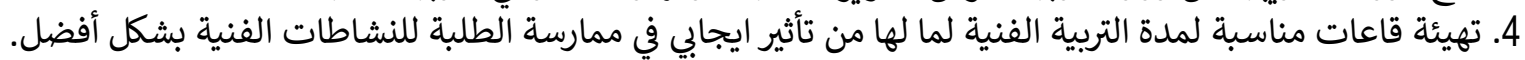

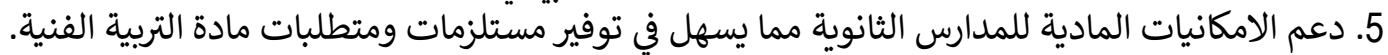

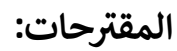
1. خصائص التكامل الفني وتطبيقاته لدى مدرسي التربية الفنية من وجهة نظر طلبة المدارس.

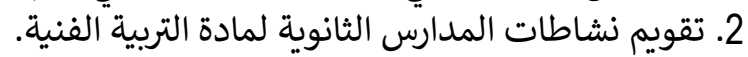
3. تنمية الخصائص المهارية لدى مدرسي التربية الفنية.

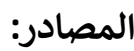

ابو الخير، جمال). 1997). طرق تدريس التربية الفنية. دار المناهج للنشر والتوزيع، عمان.

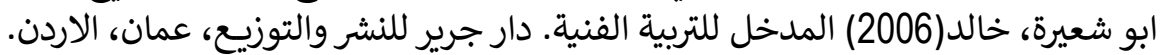

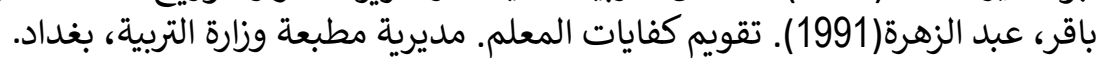

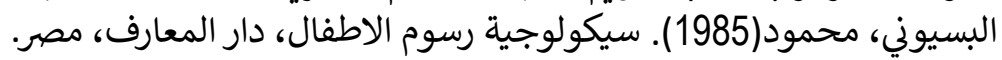

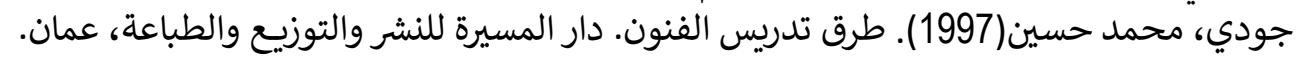
حسني، ليلى وياسر محمود (2004). مناهج وطرق تدريس الفنون دار المريس التربية الفنية بين النظرية والتوزيع والتطبيق. مكتبة الانجلو المصرية، القاهرة، مصر.

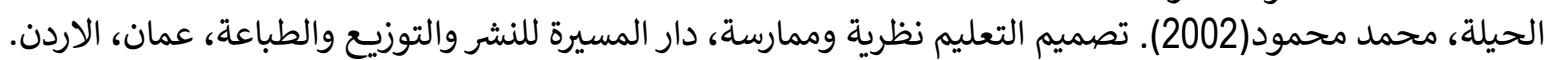

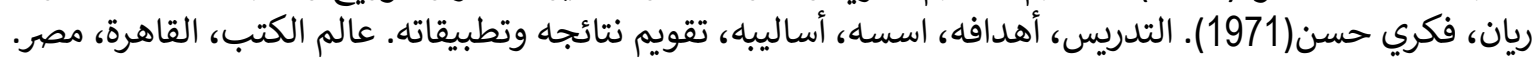

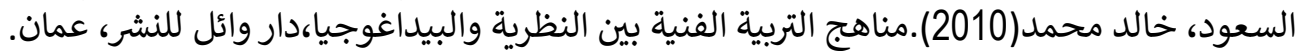

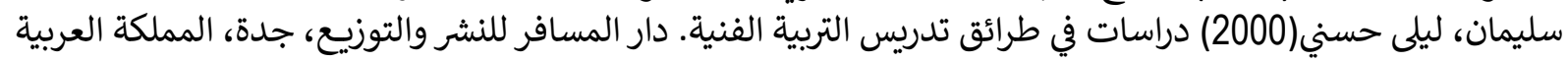

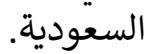

العتوم، منذر سامح (2007). طرق تدريس التربية الفنية ومناهجها، دار المناهج للنشر والتوزيع، عمان.

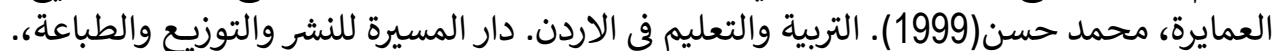

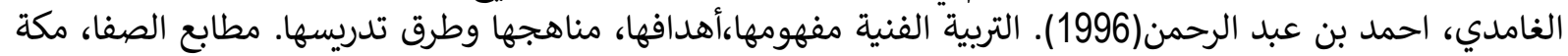
المكرمة، المملكة العربية السعودية.

كايد، عمرو(1998). خطوات ومرتكزات النقد كمقدمة المرية للخبرة الجمآلية في التربية الفنية. مجلة كلية التربية، جامعة

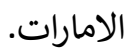

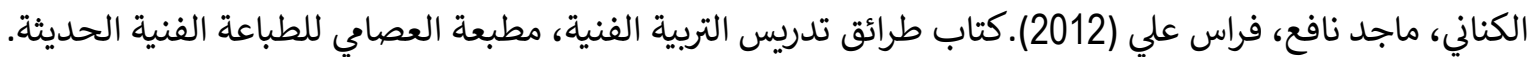

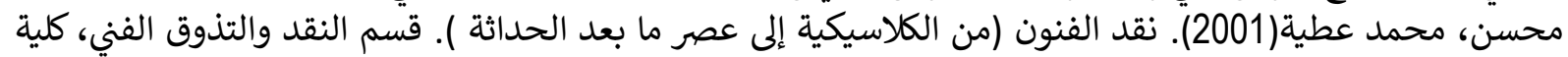
التربية الفنية، جامعة حلوان.

نجاتي، محمد عثمان(1975). علم النفس في حياتنا اليومية. دار القلم، الكويت. 
نوبلر، ناثان(1987). حوار الرؤية مدخل إلى تذوق الفن والتجرية الجمآلية. ت: فخري خليل، م: جبر ابراهيم جبر، دار

Development of cognitive research and theory, New york, Mac Millan, 1979 المأمون، بغداد.

Klein bauer, W.E. , art history in ( DBAE ). Journal of Aesthetic education , 19870 jin the life of societies and 